\title{
Project Management of an Automotive Industrial Building Using MS Project and Primavera
}

\author{
Rasikh Riyaz $^{1}$, Anuj Sachar ${ }^{2}$, and Sandeep Singla ${ }^{3}$ \\ ${ }^{1}$ Research Scholar, Department of Civil Engineering, RIMT University, Gobindgarh, Punjab, India \\ ${ }^{2}$ Assistant Professor, Department of Civil Engineering, RIMT University, Gobindgarh, Punjab, India \\ ${ }^{3}$ Professor, Department of Civil Engineering, RIMT University, Gobindgarh, Punjab, India
}

Correspondence should be addressed to Rasikh Riyaz; rasikhshah@gmail.com

Copyright (C) 2022 Rasikh Riyaz et al. This is an open-access article distributed under the Creative Commons Attribution License, which permits unrestricted use, distribution, and reproduction in any medium, provided the original work is properly cited.

\begin{abstract}
For successful completion of a project two most important factors are planning and scheduling. The construction industry requires precise planning and management that can help completing a project on given timelines and allow for the full implementation of controlled cost, time and resources. Due to increasing workloads and declining resources the construction management industry has acquired new technologies that help to manage and organize the project more easily. The Project management software is used as a management and planning tool that helps industries grow faster. There are various software available in the market like Microsoft Project, Primavera P6, etc. Good planning and project management may be done with the help of these tools. Primavera makes it simple to compare the projected progress of construction work with the actual progress of construction activity. Primavera P6, includes recording, collection, monitoring, managing and reporting projectrelated information. In this study project management and monitoring can be done and the causes of delays can be identified.
\end{abstract}

KEYWORDS- Planning, Scheduling, Project Management, Microsoft Project, Duration, Primavera.

\section{I.INTRODUCTION}

The construction industry is critical to the development of the nation's infrastructure and industrial growth. Our construction industries are dealing with a number of issues, the most common of which are excessive expenditures and overtime owing to poor project construction, implementation, planning, and management during execution. According to the research, good skill management is critical for the project to be completed on time, within the budget, and with the resources available. Providing a project with solid planning, structure, and a consistent flow of resources can result in the desired output. A warning system that can alert the organization should be available. A warning system should be available that can tell the company about the project's overall success or failure.

Project Controlling and Monitoring is a method of recording, collecting, and reporting information relating to project performance by a project team and anyone who wish to know, and it serves as a warning system. Monitoring is keeping track of the entire project's progress by looking at the time, application, and resources used during its execution and identifying areas that require immediate attention and action. Large projects become more complicated and complex, making it impossible to transmit information on paper throughout an organization at the appropriate moment. Because there is so much data and information about the project that is continuously changing, the previous project management system cannot satisfy the needs of today's projects. So we need a proper recording and controlling database software that can plan, monitor and record the construction activities.

\section{A. PROJECT MANAGEMENT}

Construction industry is one of our country's most important sectors. The industries are dealing with a number of difficulties that must be addressed. Project management is the application of knowledge, abilities, plans, and methods to execute projects easily in order to satisfy demand. Project management is divided into six stages, which are as follows:

- Project Definition: A description of the objectives and key elements of the project.

- Project Implementation: All needed is to set up the entire project before the start of the project.

- Project Planning: Detailed plans for how the work will be done, including cost, time and resource estimates.

- Project Execution: Performing the task of delivering the product, service or outcome you want.

- 5. Project Monitoring and Control: Ensure that the project remains on track and takes corrective action to ensure that it is achievable.

- Project Closure: Official approval of the release and disbandment of all project requirements.

A project is transient in the sense that it has a beginning and an end date. In other words, time is constrained but not necessarily limited; the duration of a project varies depending on the project type. The term "unique" refers to the fact that each project is distinct and has its own characteristics. Even if there are some features that are repeated, the project is unique since it has a separate owner, design location, and facilities. A project must be built gradually, which entails consistent and consistent work and growth.

Although there is a variety of software available, MSP and Primavera are the most commonly used software. Primavera is a fantastic project management tool that can be used for 
both small and large projects. We can control and monitor multiple projects at the same time with this program.

Primavera is a project management software program, it aids engineers in the development of plans, the control of project delays, and the determination of resource efficiency. Primavera is a project management software that helps you finish a project on time and on budget. All types of projects are planned, controlled, and evaluated using the Primavera system. To comprehend project management, we must first comprehend both project and management.

\section{II.RELATED WORK}

Shashwat Dubey et al. (2021) have studies that based on the findings of the numerous researches, we can conclude that planning and controlling are critical for every construction project's success. Project management aids in project forecasting. Primavera software is a project management application that allows you to track project progress and manage project activity. The primary goal of project planning is to avoid project delays. Project groups in the traditional manner are unsure about the optimal path to project completion. The results of the literature assessment show that using the Primavera tool is superior to using the traditional building method. [1]

Polekar et al. (2019) found errors editing and planning process. It was also found that subcontractors and the contractors played a major role in project completion on time, as the main reasons for the delays in completion were related to contractor's performance. [2]

Gaurav S. Narlawar et al. (2019), have studied that the project manager is in charge of ensuring the project's success and can reduce delays by using Primavera software to identify important project activities. Project management becomes more efficient with Primavera P6 software. Primavera P6 has shown to be an efficient tool for construction project monitoring and control because the time to update is greatly decreased. [3]

Abhishek Sharma (2018), have studied Using Microsoft Project 2013, resource levelling was used to analyze manpower resource restricted projects and compare time costs in residential construction. It assists in resolving resource conflicts and in reducing project time within constrained resource availability in order to make the project viable. They came to the conclusion that projects are delayed without effective resource scheduling, and that they can be levelled to reduce project duration and expense. [4] Piyush Pramod Bagade et al.(2018), have studied that Planning and scheduling aid in project forecasting. Primavera is used to determine an individual's expense as well as their usage. As a result, proper management decisions can be made. There is a risk of resource overallocation while working on many projects within the same organization; Primavera mitigates this with proper resource optimization. The resource use spreadsheet at the bottom of the project window shows overallocation of resources. Primavera software can be used to schedule realtime projects. Primavera software divides resources into three categories: i) labour, ii) machines and iii) materials. It allows us to establish our own units of measurement. Thus it was concluded that primavera is best software tool for construction project management. [5]

Ranjithkumar et al. (2017) stated that using Primavera software to plan and program activities gave extensive information on cost control, time management, working hours management, updating and monitoring, and delays in activities, all of which improved service delivery efficiency. [6]

Shah Harsh et al. (2017), have studied that using Microsoft Project 2013, resource leveling was used to analyze manpower resource restricted projects and compare time costs in residential construction. It assists in resolving resource conflicts and in reducing project time within constrained resource availability in order to make the project viable. They concluded that projects are delayed without effective resource scheduling, and that they can be leveled to reduce project duration and expense. Primavera P6 software can be used to properly plan, schedule, and track any construction project. The Primavera P6 software may be used to efficiently manage several projects. Resource smoothing and resource leveling processes benefit greatly from the Primavera P6 software. Project management with the Primavera P6 software is more efficient, time-consuming, and paper-intensive than traditional methods. The Primavera program gives detailed information on cost control, time management, working hour management, activity update and monitoring, and activity delay, all of which improve service delivery efficiency. [7]

S. Ragavil et al. (2016), have studied that the project scheduling and resource allocation were done using MSP software in the first phase, and the optimization was done by changing the manpower requirements for various jobs in the second phase to eliminate any sudden variations in manpower need. Finally, the personnel resource has been optimized by adjusting the duration of specific activities as well as predecessors without compromising the project's duration. Planning and scheduling aid in future circumstance and project implementation. While performing any activity, the Primavera Software provides user-friendly solutions. The cost and length of each individual job break down can be determined. As a result, rational judgments for proper administration can be made. Resource leveling is critical when working on many projects to ensure optimum resource allocation. Such an analysis should be performed for numerous projects under a same firm to check for over allocation. Real-time project scheduling is also a critical standard for managing many projects. [8]

\section{III.MATERIALS AND METHODOLOGY}

The approach to this industrial project mainly consists of:

- Interact with people who work in the area.

- Data collection and analysis.

- Plot and record the activities in Microsoft Project MSP

- The project can be mapped in Primavera according to the data collected from the site.

The early steps and processes that are followed when a project is awarded to a contractor and the notice to proceed is issued to contractor. This has a significant impact on the project's success. The first step in starting a new project is to create a project start-up strategy. "Pre-job planning" refers to the organization and preparation of this project approach. Pre-job planning will entail a number of aspects and variables, as well as a number of key persons who have been or will be associated with the project, depending on 
the extent and complexity of the project mobilization follows pre-job planning and comprises operations that occur prior to the start of construction. It includes organizing and mobilizing the contractor's resources, transporting and setting up equipment at the project site, and establishing temporary structures including offices, site utilities, and storage, among other things. A premobilization visit to the site should be made by members of the project team. Before any firm equipment, facilities, or staff occupy the site, the owner's consent must be secured in writing. The following are the primary tasks that must be completed in order to achieve project mobilization:

Before any corporate equipment, facilities, or staff occupy the site, all normal project insurances must be in place. Before putting up any equipment or starting any work, a photographic or video survey of the project site must be done. A site use plan should be created, which includes the location of the field office, planned access, material storage, fueling and/or chemical storage spaces, and subcontractor storage, among other things.

A pre-construction conference is held after the project has been mostly mobilized and before construction operations begin as part of good construction project management procedures. The owner/representative designer's and the contractor's project manager usually co-chair this meeting. The goal of this meeting is to create project ground rules so that each project team member is aware of the project's administrative requirements and decides on a communication/reporting system.

\section{DATA ANALYSIS AND INTERPRETATION}

As a project team we consulted with the site developer and ensured that the data provided was accurate and took the verification values into the Microsoft Project and Primavera p6 software. We edited and adopted the report form accordingly. The scope of data collection is separated into the next step:

- Study the area features.

- Using Primavera to create the project's real schedule.

- Identifying the project's limits.

- Reducing constraints that could cause delays and creating a new timeline.

- Optimize labour resources to lower the project's overall cost.

- Find out whether there is any space available.

- Organizing the workstation.

- Reports are collected once a week for the workspace assigned.

- For each and every work and material, a report must be made.

\section{A. PROJECT DOCUMENTATION}

Several forms of documentation are necessary to be maintained in a typical construction project. The goal of project documentation is to keep track of project information that can help in project management. Documents must be in legal format, factual, and consistent so that prior reports may be compared. The following are some of the most common forms of project documents:

- Progress reports and daily logs

- Reports on testing

- Photographic images
- Reporting of accidents

- As-built blueprints

- Transmittals and submittals

- RFIs (Requests for Information) are a type of request for information that (RFI)

- Messages on the phone and letters

- Correspondence, job drawings, shop drawings, payment applications, and samples from the construction field office

\section{B. CLOSEOUT OF THE PROJECT}

Finishing a project is frequently more difficult than starting it. If a project team fails to understand this issue and design a realistic completion strategy, otherwise successful project can come to a very unpleasant end. The ability to "complete" a project rather than "wear it out" is critical to a company's image. Successful companies have precise protocols in place to handle this process as well as the other phases of a project.

Following points to be noted:

- Make a uniform checklist of closeout duties and procedures.

- Procedures for reconciling modification orders, back charges, retain ages, lien releases, and final payments to complete off subcontracts and purchase agreements.

- Procedures for deleting and archiving project records and files.

- When the final payment is received and the project is completed, procedures to shut project cost accounts are followed.

- After "completion," create warranty item accounts for the work.

- Work with the owner's facilities staff to schedule equipment and facility training courses.

- Provide the owner with as-built drawings, operations and maintenance instructions, and warranties.

- Organize project files for transfer to the home office.

- With the owner's representative, conduct pre-punch list, punch list, and final inspections.

- Organize keying schedules

- Certificates of code compliance should be provided.

- Lien waivers and surety approval for final payment

- Submit a request for payment in full.

\section{Use of MS Project and PRIMAVERA in the Project}

The most extensively used software for scheduling, planning, tracking, and reporting are Primavera and MS Project. The significant differences between these two pieces of software are detailed below.

\section{1) User Interface}

Oracle Primavera has an excellent user interface, including graphs, but Primavera P6 Professional and other versions have a weaker User Interface. In contrast, MS Project is a powerful Graphical User Interface with captivating progress graphs, resources graphs, and histograms in MS Project and other packages.

\section{2) Multiple User Access}

Primavera allows for multiple user access and allows users to define which Primavera features they must use. While MS Project does not support multiple users, the server can 
support numerous projects at the same time, however the user is left without a project when it is in use.

\section{3) $W B S$}

WBS is developed apart from activities in Primavera. We can then add activities for each element to the WBS once it has been established. In MS Project, however, activities are indented to resemble a WBS

\section{4) Advantages of Primavera}

- Forecasting is simple: It enables project managers to quickly develop reliable project forecasts and communicate them with corporate leaders or stakeholders.

- Worker Access and Responsibility: It gives employees the ability to set schedules, request timesheets, and submit them whenever they want.

- Great Visibility: It allows users to analyze data in one place to ensure that the project complies with all applicable norms and guidelines as shown in Fig 1.

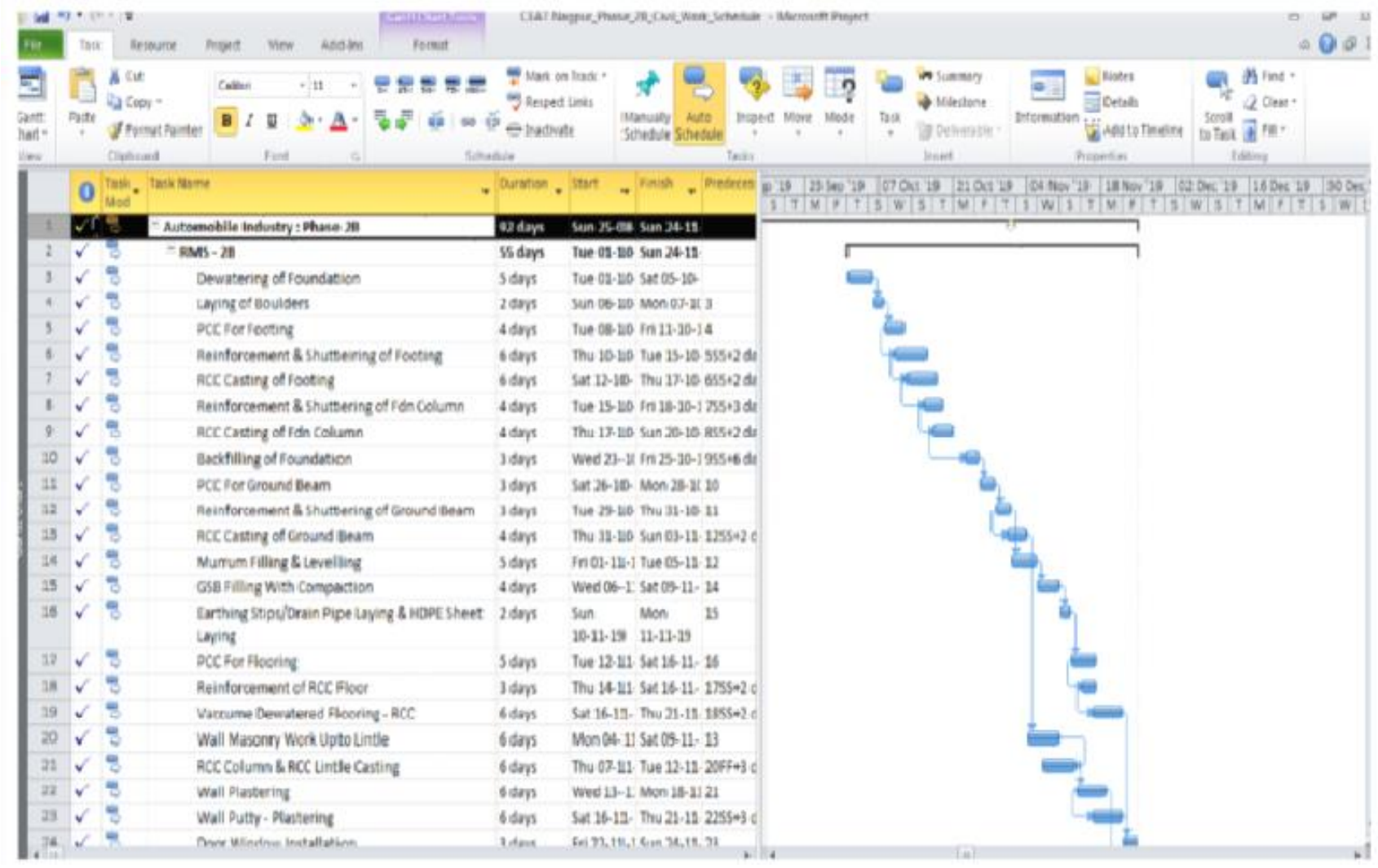

Figure 1: Mapping MSP activities in Primavera P6

\section{5) Advantages of MS Project}

- User Friendly Interface: MS Project has a very userfriendly interface that allows you to get the most out of its features and functions. It allows users to work on new tasks or project revisions at any time without being interrupted as shown in Fig 2
- High Visibility: It provides a 360-degree view of project information, as well as scheduling tools such as Gantt charts and flexible menus for efficient project planning.

- Pre-installed templates: It provides pre-installed templates based on user requirements to assist users in quickly creating a project plan 


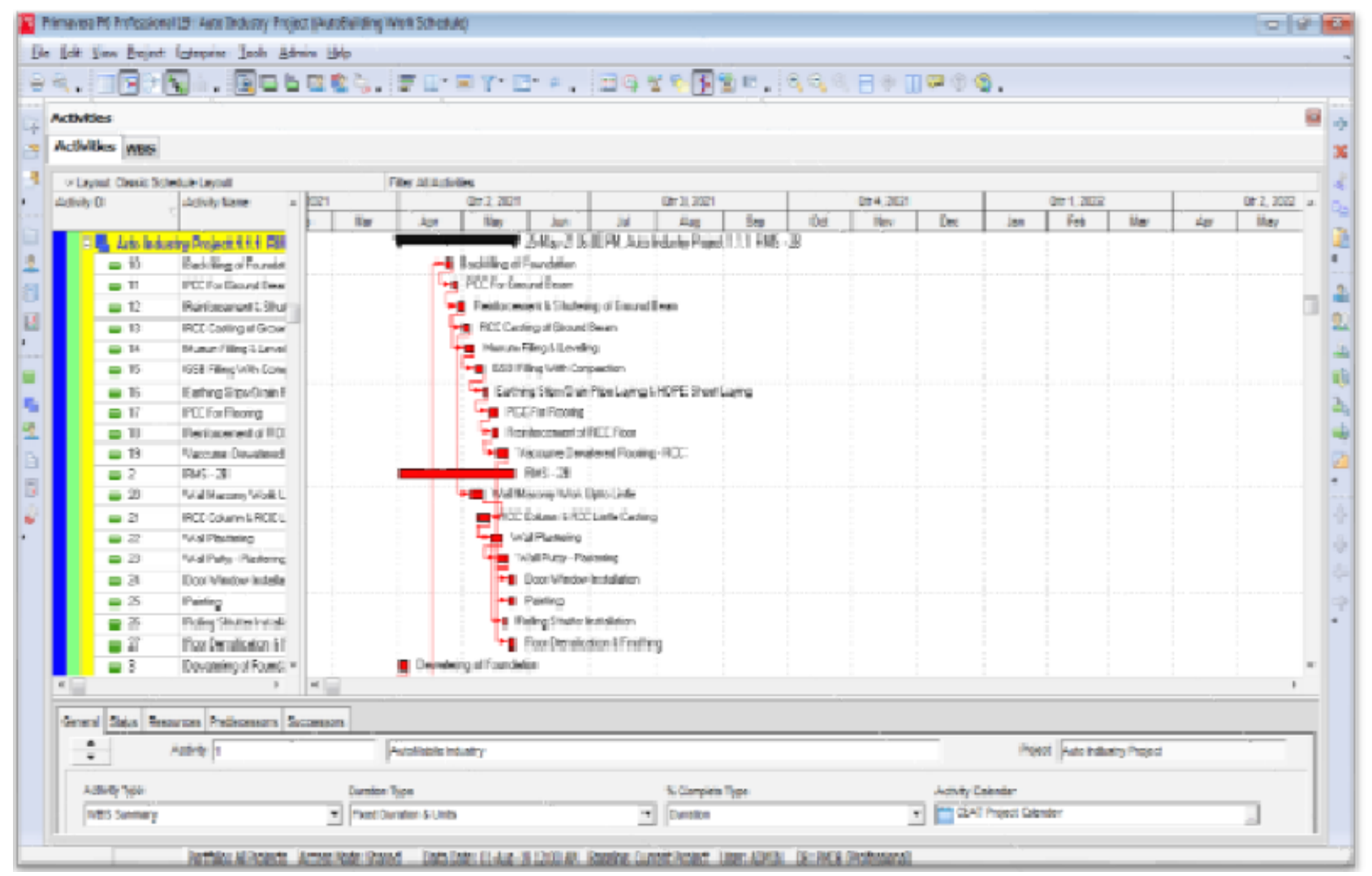

Figure 2: Planning and management using MS Project

\section{V.CONCLUSION}

The study concludes that both Primavera and Microsoft Project are well-known project management software that support project goals and organizational needs. It's difficult to distinguish one tool from another because they both have different tactics and characteristics. We should identify which software helps fulfil the unique project services to offer a high-quality CPM schedule based on the project needs. Each tool has its own set of features, but they all work toward the same goal providing professional construction management services. The Industrial project was tracked both in MS Project and Primavera P6 and both the software helped to track the construction activities smoothly. However Primavera allows numerous people to collaborate on a project while also defining the features that must be used. It also facilitates the creation of numerous activity interactions in which more than one sort of relationship between the activities can be established.

\section{REFERENCES}

[1] Raiyan Abdul Rashid Mansoori(2016), " Application of Primavera \& GIS for Effective Project Management," International Journal of Engineering Research, Volume No.5,pp(140-142).

[2] Dubeiy Anuj (2016), "Earned Value Analysis For a Construction Project Management", (IJCIET), ISSN 0976 - 6308 (Print), ISSN 0976 - 6316, Volume 6, Issue 6

[3] B. S. K. Reddy, SK. Nagaraju, Md. Salman(2015), "A Study On Optimisation of Resources for Multiple Projects by Using Primavera" Journal of Engineering Science and Technology,Vol.10

[4] Magdalene Benila ,R Esakki Thangam P, (2015), "Planning, Scheduling and Time Management of Six Lanes Road Construction Work at V.O.C Port Trust using Primavera P6
Software", (IJSTE), ISSN (online): 2349-784X, Volume 2, Issue 11

[5] Dixit R K , Verma Ankur, Pathak K K, Dixit R K (2015), "Earned Value Analysis of Construction Project at Rashtriya Sanskrit Sansthan, Bhopal", (IJIRSET), ISSN: 2319-8753, Vol. 3, Issue 4

[6] Pethe Sarang S, Pramila Adavi(2012)," Application Of PRIMAVERA In Construction Industry," International Journal of Advanced Technology in Civil Engineering, Volume-1, pp( 16-17)

[7] Vijay K, Rajendra S Mohammed ,Zaki Haider, (2014), "Planning Scheduling, Tracking And Application Administration Using Primavera Web Logic P6", (IJRET), p ISSN: 2321-7308, Volume: 05, Issue: 07

[8] Robichaud, L. B., \& Anantatmula, V. S. (2010), Greening project management practices for sustainable construction. Journal of Management in Engineering, 27(1), 48-57

[9] James P. Lewis (2000), the project manager's desk reference: a comprehensive guide to project planning, scheduling, evaluation, and systems. Pp.185-256. 